\title{
Material standard of living, social class, and the prevalence of the common mental disorders in Great Britain
}

\author{
Scott Weich, Glyn Lewis
}

\begin{abstract}
Study objective-To test the hypothesis that poor material standard of living is independently associated with the prevalence of the common mental disorders after adjusting for occupational social class, and to estimate the population impact of poor material standard of living on the prevalence of these disorders. Design-Cross sectional survey. Prevalence of the common mental disorders was assessed using the General Health Questionnaire, a self administered measure of psychiatric morbidity.

Participants-9064 adults aged 16-75 living in private households in England, Wales, and Scotland.

Main results-The common mental disorders were significantly associated with poor material standard of living, including low household income (OR 1.24, 95\% CI 1.00, 1.54) and not saving from income (OR 1.29, 95\% CI 1.15, 1.45), after adjusting for occupational social class and other potential confounders. An independent association was also found with occupational social class of the head of household among women, but not men, after adjusting for material standard of living. The adjusted population attributable fraction for poor material standard of living (using a five item index) was $24.0 \%$.

Conclusions-Like mortality and physical morbidity, common mental disorders are associated with a poor material standard of living, independent of occupational social class. These findings support the view that recent widening of inequalities in material standards of living in the United Kingdom pose a substantial threat to health.
\end{abstract}

(F Epidemiol Community Health 1998;52:8-14)

Royal Free Hospital School of Medicine, London

S Weich

University of Wales College of Medicine, Cardiff

G Lewis

Correspondence to: Dr S Weich, University Department of Psychiatry, Royal Free Hospital, Schoo of Medicine, Rowland Hill Street, London NW3 2PF.

Accepted for publication 7 March 1997. mental health, many of whom do not receive or want treatment from doctors, but in whom there is a considerable degree of suffering, social disability, ${ }^{9-12}$ and increased mortality. ${ }^{101314}$ Though known by a variety of alternative names in the past, including neuroses, minor psychiatric morbidity, nonpsychotic psychiatric morbidity, and demoralisation, we have chosen to use the term "common mental disorders", 3 on the grounds that it is descriptive, non-pejorative, and emphasises the public health importance of these disorders. In addition to their high prevalence, the common mental disorders account for more than one third of days lost from work because of ill health ${ }^{15}$ and one fifth of general practice consultations in the United Kingdom. ${ }^{7}$ The total annual cost of these disorders in the UK may amount to $£ 6$ billion, of which two thirds is attributable to lost productivity. ${ }^{16}$ One study found that the prevalence of these conditions may have increased in recent years. ${ }^{17}$

Although they are most prevalent among those with the lowest material standard of living, ${ }^{3618-22}$ inconsistencies have been reported in the association between common mental disorders and occupational social class. ${ }^{18} 192123-26$ It has not yet been established whether, like mortality, ${ }^{27-30}$ the association between the prevalence of the common mental disorders and material standard of living exists within all occupationally defined social strata. This question has important public health policy consequences. Though positively correlated with income, occupational social class is largely a measure of social status, and is probably an inevitable consequence of the division of labour. Material standard of living, on the other hand, is a more direct measure of "command over resources". ${ }^{28}$ Thus, differences in material standard of living are likely to be more amenable to amelioration through social and economic interventions than differences in occupational status.

This study was designed to test the hypothesis that the association between the prevalence of the common mental disorders and poor material standard of living is independent of social status as measured by occupational social class. We also estimated the population impact of poor material standard of living on the prevalence of common mental disorders. Secondary analysis of the British Household Panel Survey was undertaken because of its detailed information on material standard of living. 
Methods

In the British Household Panel Survey (BHPS), ${ }^{31}$ households were selected for inclusion based on an equal probability sample of the population of Great Britain (England, Wales, and Scotland south of the Caledonian canal), using a two stage stratified cluster design with postcode sectors as primary sampling units. ${ }^{32}$ Within selected households information was gathered on all household members, and efforts were made to interview all those aged 16 and over. The first wave of BHPS interviews took place between September and December 1991.

Common mental disorders were assessed using the self administered 12 item General Health Questionnaire (GHQ). ${ }^{33}$ The GHQ was designed as a case finding instrument for use in primary care and community settings, and it has been widely validated against standardised clinical interviews. ${ }^{33}$ Previous community surveys, using a variety of measures, have shown consistently that symptoms of anxiety and depression are continuously distributed and are more validly represented by dimensional than categorical models. Principal components analyses have shown that the greatest proportion of variance in the distribution of these symptoms (typically of the order of $35 \%$ to $50 \%$ ), is accounted for by a single, general factor described as "illness severity" or "general dysphoria".13434-36 Furthermore, these data are equally well described by models comprising either one factor or two highly correlated factors, corresponding to anxiety and depression. ${ }^{13}$ In keeping with many previous community studies, ${ }^{17-18} 263738$ we chose to treat the common mental disorders as a single dimension. The GHQ score can therefore be considered "an assessment of an individual's position on an axis from normality to undoubted illness, ... giving a probability estimate of that individual being a psychiatric case". ${ }^{33}$ Those scoring 3 or more on the GHQ were classified as cases, ${ }^{39}$ and although results are presented here for "cases" of common mental disorders, there was no reason to expect that using GHQ scores as a continuous variable would lead to different results. ${ }^{40}$

Registrar General's social class was recorded for each person and their head of household, ${ }^{32}$ based on current or most recent occupation. Childhood social class was defined according to father's occupation when the subject was aged 14 . Seven variables were selected a priori to provide a comprehensive yet parsimonious assessment of each subject's material standard of living: (1) annual household income adjusted for household size using the $\mathrm{McCle}$ ments Equivalences Scales, ${ }^{32}$ by fifths within the region of residence; (2) saving from income, excluding money put by to pay bills but including life insurance, personal equity plans (PEPs), share purchases, and saving for holidays; (3) access to car/ van within household, (4) number of domestic household appliances, out of possible list of nine including colour television, video recorder, and microwave oven, (5) housing tenure, (6) overcrowding (more than two household members per
KEY POINTS

- Common mental disorders were associated with low material standard of living within all occupationally defined social strata.

- The social class gradient in the common mental disorders was stronger among women, and increased with age in both sexes.

- Poor material standard of living, which is potentially remediable, accounted for nearly one quarter of prevalent cases of common mental disorder.

bedroom), and (7) the presence and number of structural housing problems, namely damp, condensation, leaking roof, and/or rot in wood. As the cost of living differs between regions of Britain, ${ }^{41}$ household income relative to others in the same region was chosen on the grounds that it is probably a more sensitive measure of "command over resources" 28 than income relative to others in Britain as a whole.

Where income sources could not be verified by documentary evidence, missing data were imputed by the BHPS investigators, ${ }^{32}$ and these values were used in this study to reduce potential bias arising from the exclusion of missing data. Annual household income was constructed from data on individual incomes. Missing labour income data were imputed using the regression based technique known as predictive mean matching. Firstly, the best fitting linear regression model (in terms of maximal adjusted $r^{2}$ ) for household income was identified among valid (that is, non-missing) cases using non-missing variables and, where appropriate, other imputed variables. These models typically have of the order of 60-70 predictor variables. This equation was then used to calculate the predicted household income for all cases. The real value for a valid case that was closest to the predicted value for a missing case was identified, and taken as the imputed value for the missing case. Non-labour (for example, benefit) income, and full incomes for non-respondents, were imputed using hot-deck models, which are analogous to weighting classes. Imputation classes based on individual and household sociodemographic characteristics were identified that were found to be predictive of the variable to be imputed, using a program capable of handling a large number of classification variables. Assuming that cases within each class comprise a random sub-sample of the population, a valid value of the variable from a non-missing case was imputed for a missing case. By imputing a real value with a random error component whose variance is similar to that of (actual) reported values, these imputation methods minimise any tendency to over-predict associations with income. $^{32}$

Variables from the BHPS dataset selected for analysis because of their possible association with the prevalence of common mental disorders and material standard of living were marital status, education, employment, ethnicity, 
Table 1 Unadjusted odds ratio (95\% CI) for common mental disorders among subjects in social classes IV and V compared with social classes I and II (head of household) by age and sex, and adjusted for material standard of living ${ }^{\star}$

\begin{tabular}{|c|c|c|c|c|}
\hline \multirow[b]{2}{*}{ Age } & \multicolumn{2}{|l|}{ Men } & \multicolumn{2}{|l|}{ Women } \\
\hline & Unadjusted OR $(95 \%$ CI) & Adjusted OR (95\% CI) & Unadjusted OR $(95 \%$ CI) & Adjusted OR (95\% CI) \\
\hline $16-35$ & $0.93(0.64,1.35)$ & $0.74(0.49,1.10)$ & $1.37(1.01,1.86)$ & $1.05(0.75,1.47)$ \\
\hline $36-55$ & $1.22(0.85,1.75)$ & $0.85(0.57,1.28)$ & $1.82(1.31,2.52)$ & $1.40(0.98,2.01)$ \\
\hline $56-75$ & $2.27(1.36,3.82)$ & $1.66(0.90,3.05)$ & $2.48(1.65,3.72)$ & $1.62(1.03,2.55)$ \\
\hline LRT $\chi^{2}(\mathrm{df}) \dagger$ & & $0.39(2)$ & & $6.79(2)$ \\
\hline $\mathrm{p}$ Value & & $\mathrm{p}=0.82$ & & $\mathrm{p}=0.03$ \\
\hline
\end{tabular}

*Household income within region, savings from income, housing tenure, structural housing problems, and access to car or van. tLikelihood ratio statistic (degrees of freedom) and $\mathrm{p}$ value calculated on removing "social class" variable from logistic regression model.

household size, responsibility for dependent children under the age of 16 , age of the youngest child in the household, number of current physical health problems, and region of residence. These variables were selected a priori, where review of the literature showed evidence of associations with the prevalence of common mental disorders, and where it was probable that a variable would also be associated with poor material standard of living.

STATISTICAL METHODS

Univariate differences between groups were tested using $\chi^{2}$ tests. Unadjusted and adjusted odds ratios with $95 \%$ confidence intervals, and likelihood ratio tests to assess departure from linear trends, confounding and effect modification were calculated by means of logistic regression, using Stata. ${ }^{42}$ All regression analyses were conducted using Huber weights to control for the clustering of respondents within households. $^{43}$

All seven material standard of living variables were entered simultaneously into a logistic regression analysis, with common mental disorders as the dependent variable. Those variables that were independently associated with this outcome after adjusting for all of the other material standard of living variables were then combined in a single index of poor material standard of living (see results). One point was scored for each of the following: income below the bottom quintile for region of residence, not currently saving from income, living in rented accommodation, no access to car or van, and living in property with at least one major structural problem, or two minor problems. This index was used (a) to test whether the association between material standard of living and the prevalence of the common mental disorders was modified by either age or sex, and (b) to estimate the total population attributable fraction (PAF) for poor material standard of living.

The extent of colinearity between the seven material standard of living variables, which can result in an increase in standard of errors of regression coefficients, was measured by examining the proportion of variability in household income explained by the other six variables. The inverse of $\left(1-r^{2}\right)$ for household income in a regression on the other material standard of living variables, referred to as the variance inflation factor (VIF), was then calculated. It has been suggested that a VIF $\geqslant 10$ is of concern. ${ }^{44}$

In general, the PAF for an exposure $\mathrm{k}$ may be calculated by:

$\operatorname{PAF}_{\mathrm{k}}=\mathrm{p}_{\mathrm{k}}{ }^{\prime}\left(\theta_{\mathrm{k}}-1\right) / \theta_{\mathrm{k}}$

where $p_{k}$ ' is the proportion of cases exposed to $\mathrm{k}$ (or level $\mathrm{k}$, for an exposure with multiple levels) and $\theta_{\mathrm{k}}$ is the risk ratio for people exposed to $k$, compared with the baseline group. The total PAF for poor material standard of living was estimated as the sum of the PAFs for each level of the five point index described earlier. PAFs were calculated using adjusted risk ratios, rather than odds ratios as the latter were always numerically greater than corresponding risk ratios. As the prevalence of common mental disorders was too great to satisfy the "rare disease" assumption, the use of odds ratios would have led to overestimates of respective population attributable fractions. Risk ratios were estimated using logistic regression coefficients. The odds of being a case of the common mental disorders for a given exposure was estimated by multiplying the appropriate odds ratio by

Table 2 Odds ratios (95\% CI) for common mental disorders by housing tenure, saving from income, access to car/van, household income within region of residence, and structural housing problems (1) adjusted for one another, (2) adjusted for age, sex, social class (head of household) and the interactions between sex and social class and between age and social class, and (3) adjusted for all of the preceding variables and other potential confounders*. The final column shows the PAF\% for each measure of (low) material standard of living, adjusted for variables described in (3) above

\begin{tabular}{|c|c|c|c|c|c|}
\hline & $\%$ Exposed (n) & $\begin{array}{l}\text { Adjusted OR (1) }(95 \% \\
\text { CI) }\end{array}$ & $\begin{array}{l}\text { Adjusted OR (2) }(95 \% \\
\text { CI) }\end{array}$ & $\begin{array}{l}\text { Adjusted OR (3) }(95 \% \\
C I)\end{array}$ & $\begin{array}{l}\text { Adjusted } P A F \% \\
\text { (3) }\end{array}$ \\
\hline Rented accommodation & $28.4(2725)$ & $1.24(1.10,1.40)$ & $1.27(1.11,1.45)$ & $1.19(1.04,1.36)$ & 4.92 \\
\hline Not saving from income & $57.9(5327)$ & $1.43(1.29,1.59)$ & $1.39(1.24,1.56)$ & $1.29(1.15,1.45)$ & 13.32 \\
\hline No access to car or van & $39.9(3832)$ & $1.14(1.02,1.27)$ & $1.06(0.94,1.19)$ & $0.95(0.83,1.08)$ & - \\
\hline \multicolumn{6}{|l|}{ Household income withing region } \\
\hline Top fifth & $21.2(2043)$ & 1.00 & 1.00 & 1.00 & - \\
\hline Middle three fifths & $61.0(5864)$ & $1.16(1.00,1.34)$ & $1.15(0.99,1.34)$ & $1.13(0.96,1.31)$ & 5.99 \\
\hline Bottom fifth & $17.8(1707)$ & $1.45(1.21,1.74)$ & $1.48(1.20,1.82)$ & $1.24(1.00,1.54)$ & 4.03 \\
\hline $\begin{array}{l}\geqslant 2 \text { minor/any major structural housing } \\
\text { problems } \dagger\end{array}$ & $25.4(2430)$ & $1.53(1.36,1.74)$ & $1.47(1.29,1.69)$ & $1.40(1.22,1.60)$ & 8.00 \\
\hline $\operatorname{LRT} \chi^{2}(\mathrm{df}) \ddagger$ & & - & $154.41(7)$ & $67.33(7)$ & \\
\hline $\mathrm{p}$ Value & & & $\mathrm{p}<0.00001$ & $\mathrm{p}<0.0001$ & \\
\hline
\end{tabular}

${ }^{\star}$ Employment status, household size, responsibility for dependent children, education, ethnicity, marital status, number of physical health problems, and region of residence. †Compared with no structural housing problems. $\ddagger$ Likelihood ratio statistic (degrees of freedom) and $\mathrm{p}$ value calculated for the combined effect of the five "material standard of living" variables in the table. 
Table 3 Distribution of study sample and cases of common mental disorders by score on five point index of low material standard of living, showing individual effect (prevalence of disorder, odds ratio (OR), and risk ratio (RR)) and population impact (population attributable fraction, PAF\%)

\begin{tabular}{|c|c|c|c|c|c|c|}
\hline Score & $\%$ Subjects (n) & $\%$ Cases among exposed $(n)$ & $\%$ Total cases & Adjusted $O R^{\star}(95 \%$ CI $)$ & Adjusted $R R^{\star}$ & Adjusted $\mathrm{PAF} \%$ * \\
\hline 0 & $21.3(1930)$ & $16.6(321)$ & 14.4 & 1.00 & 1.00 & - \\
\hline 1 & $31.1(2820)$ & $21.9(617)$ & 27.7 & $1.26(1.08,1.48)$ & 1.22 & 4.99 \\
\hline 2 & $22.5(2037)$ & $24.8(506)$ & 22.7 & $1.36(1.15,1.62)$ & 1.29 & 5.10 \\
\hline 3 & $14.4(1305)$ & $30.8(402)$ & 18.0 & $1.67(1.37,2.04)$ & 1.51 & 6.09 \\
\hline 4 & $8.0(728)$ & $37.5(273)$ & 12.3 & $2.03(1.59,2.61)$ & 1.76 & 5.29 \\
\hline 5 & $2.7(244)$ & $45.1(110)$ & 4.9 & $2.51(1.77,3.55)$ & 2.05 & 2.53 \\
\hline Total & 100.0 & - & 100.0 & - & - & 24.00 \\
\hline
\end{tabular}

^Adjusted for age, sex, social class (head of household) and the interactions between sex and social class and between age and social class, and employment status, household size, responsibility for dependent children, education, ethnicity, marital status, number of physical health problems, and region of residence.

the antilog of the constant term, which represents the estimated odds of being a case for those in the baseline category. The risk ratio is calculated by dividing the probability of being case given the exposure in question by the probability of being a case in the baseline category where probability, $\Pi$, is derived from the odds, $\Omega$, as follows: $\Pi=\Omega / 1+\Omega$.

\section{Results}

After excluding non-existent addresses, empty, derelict or business properties, $73.6 \%$ of households $(n=5511)$ participated in the first wave of the survey, comprising 10264 people aged 16 and over. The GHQ was completed by $94.3 \%(\mathrm{n}=9064)$ of interviewed persons aged $16-75$. Social class by self and by head of household could not be classified in $11.3 \%$ and $11.5 \%$ of cases respectively, and were treated as missing. Annual household income was partly imputed for $30.0 \%$ of households, and wholly imputed for $12.5 \%$ of households. Compared with the $1 \%$ sample of anonymised records (SARs) based on the 1991 census, people aged $55-64(9.3 \%$ of BHPS subjects $v 10.3 \%$ of SARs), Asians (1.9\% v 2.9\%), the single (never married) $(25.1 \% \vee 28.5 \%)$, households with six or more people $(1.9 \%$ v $2.5 \%)$, and those without access to a car or van $(31.0 \%$ v $33.3 \%)$ were underrepresented in the BHPS sample to a statistically significant degree. ${ }^{45}$ The prevalence of common mental disorders in the study sample was $24.6 \%$ (23.7-25.5).

COMMON MENTAL DISORDERS AND SOCIAL CLASS Both own social class $\left(\chi^{2}=18.99, \mathrm{df}=2\right.$, $\mathrm{p}<0.0001)$ and that of the head of household $\left(\chi^{2}=29.38, \mathrm{df}=2, \mathrm{p}<0.0001\right)$, but not paternal social class, were associated with common mental disorders. Social class by head of household was independently associated with common mental disorders after adjusting for own social class, while the association between common mental disorders and own social class ceased to reach statistical significance. There was a stronger relation between social class by head of household among women, and this interaction reached statistical significance $\left(\chi^{2}=5.84, \mathrm{df}=2, \mathrm{p}=0.05\right)$. No such interaction by sex was found for own social class $\left(\chi^{2}=3.60\right.$, $\mathrm{df}=2, \mathrm{p}=0.17$ ). In older subjects there was a stronger association between low social class by head of household and common mental disorders $\left(\chi^{2}\right.$ for age $\times$ social class interaction $=14.62, \mathrm{df}=4, \mathrm{p}=0.006)$ for both men and women (table 1). The association between social class by head of household and common mental disorders was confounded by age and material standard of living among men, but not women (table 1).

COMMON MENTAL DISORDERS AND MATERIAL STANDARD OF LIVING

Although statistically significant univariate associations were found between common mental disorders and all seven of the measures of (poor) material standard of living, five variables were independently associated with common mental disorders after adjusting for the other measures of material standard of living: not saving from income, low household income, structural housing problems, living in rented accommodation, and no access to a car or van. When regressed on household income, the proportion of variability accounted for by the other four variables was 0.17 , and the VIF, a measure of collinearity between these variables, was 1.21 (see methods).

Housing tenure, savings from income, structural housing problems, and household income were independently associated with the prevalence of common mental disorders, after adjusting for age, sex, social class (head of household), the interactions between sex and social class and between age and social class, and other potential confounders (table 2).

A statistically significant trend was found between common mental disorders and score on the five item index of poor material standard of living (see methods) $\left(\chi^{2}=79.03, \mathrm{df}=1\right.$, $\mathrm{p}<0.0001$ ), which did not depart from linearity to a statistically significant degree $\left(\chi^{2}=2.67\right.$, $\mathrm{df}=4, \mathrm{p}=0.61)$. Unlike occupational social class, no statistically significant interactions were found between any of the indices of material standard of living (including score on the five item index of poor material standard of living) and either sex or age in their associations with common mental disorders. This finding was also unaffected by whether the five item "material standard of living" score was treated as a categorical or continuous variable. For this reason estimates of associations between material standard of living and common mental disorders are combined for men and women (table 2). The total PAF for poor material standard of living was $24.0 \%$ (table 3 ), and the largest PAF for an individual item was $13.32 \%$, for not saving.

\section{Discussion}

Poor material standard of living was independently associated with the prevalence of common mental disorders, and accounted for nearly one quarter of all cases, after adjusting 
for occupational social class and a large number of other potential confounders. As these findings are based on cross sectional data, it is not possible to distinguish between factors associated with increased incidence of disorder, those associated with increased duration of episodes, and those that were the consequence of common mental disorders (reverse causality). The latter is particularly difficult to exclude as an explanation for the findings, because the common mental disorders often relapse and remit over many years. ${ }^{3}$ However, it is notable that previous studies have indicated that the contribution of social selection to the socioeconomic gradients in the prevalence of the common mental disorders is likely to be modest. ${ }^{25} 46$ Although our findings must be interpreted cautiously, we would argue that it is perfectly valid to study associations between socioeconomic risk factors and the prevalence of the common mental disorders. Indeed, this is especially important in the case of the common mental disorders, where a principal public health aim must be to reduce the prevalence of conditions that are chronic or recurrent. In this respect, the population attributable fraction, a measure of the population impact of specific risk factors, should be viewed as an indication of the maximum reduction in prevalence that might be achieved were it possible to remove these risk factors, or to ameliorate their adverse psychological effects.

As in previous studies, ${ }^{18} 1921232426$ the association between occupational social class and the prevalence of the common mental disorders proved complex, and was modified by both age and sex. In summary, this association was stronger among women and those aged 56-75, compared with men and younger subjects, respectively. Overall, the association with occupational social class was wholly confounded by material standard of living for men (including those aged 56-75), but not women. The interaction between social class and age was of a similar magnitude for men and women, and is consistent with previous findings. ${ }^{18} 2123$ Possible explanations include a modifying effect of life stage $^{21}$ or a cohort effect, or both. In support of the former is the likelihood that differences in material standard of living between occupational social class strata increase with age, as those in higher social classes are more likely to have occupational or private pensions. This is consistent with the confounding of the occupational social class gradient in the prevalence of common mental disorders by material standard of living at all ages, an effect that was more pronounced for men than women.

As our analyses were based on household income and the occupational social class of the head of household, for the reasons set out earlier, and as our sample included the retired, the unemployed, and those not in work for other reasons, our findings indicate that the socioeconomic gradient in the prevalence of common mental disorders results predominantly from differences in material standard of living, rather than differences in social status or other factors associated with specific occupations.
The study was limited by the use of the GHQ as a measure of psychiatric morbidity, rather than a standardised clinical interview, though the GHQ has been validated extensively in community settings. ${ }^{33}$ The estimated prevalence of common mental disorders in this study $(25 \%)$ was higher than that of a recent British community survey (14\%) using a standardised clinical interview. ${ }^{6}$ This probably reflects a lower threshold of severity of the GHQ. The GHQ is sensitive to recent change in psychological well being and functioning, and "false positives" among our cases (relative to the assumed "gold standard" of a standardised clinical interview) will have included people with mild and transient psychological disturbance. Because associations between poor material standard of living and the prevalence of the common mental disorders seem robust regardless of the measure of psychiatric morbidity used, ${ }^{6} 202248$ and are generally of greater magnitude when standardised clinical interviews have been used to identify cases, ${ }^{62}$ it seems probable that the inclusion of mild, self limiting cases would have biased risk ratios in this study towards unity. Furthermore, because the proportion of the population exposed to poor material standard of living is unaffected by the choice of outcome measure, any tendency in this study to overestimate the prevalence of common mental disorders while underestimating the risk ratio for this exposure would have resulted in an underestimate of the population attributable fraction. Thus, we predict that studies using standardised clinical interviews would find that a greater proportion of cases would be attributable to poor material standard of living than in this study. The other important source of false positives on the GHQ is physical ill health, but the association between material standard of living and common mental disorders remained after adjusting for current physical health. Finally, it should be pointed out this dataset was selected for secondary analysis because of the comprehensiveness of socioeconomic information about people and their households. What may have been lost in clinical detail is at least partly made up for in the quality of information about potential risk factors.

Those in lower occupational grades ${ }^{26}$ and, to a lesser extent, men $^{49}$ have been found to underreport psychiatric symptoms on the GHQ compared with responses to a standardised psychiatric interview. This could explain the absence of a social class gradient in men, but it cannot explain the association with poor material standard of living.

Total annual income was imputed for a high proportion of households, because interviewers were only allowed to record information for which there was documentary evidence. Although the imputation techniques that were used minimised any tendency to overestimate the strength of associations with household income, we cannot exclude the possibility that this may have biased our results. This was unlikely, however, and would have required that both the likelihood of being a case of the common mental disorders and associations 
between the predictors of income and actual income were different for those with missing data on household income. Furthermore, any random misclassification would have biased the association between household income and common mental disorders towards the null. Indeed, this association could have been overestimated only if those with missing income data were more likely to be cases of the common mental disorders and imputed income was systematically underestimated relative to actual income, or if subjects with missing income data were less likely to be cases and imputed income was systematically overestimated.

Finally, non-response bias must be considered as an explanation for the observed associations, because only $74 \%$ of households participated and the GHQ was not completed by a further $6 \%$ of those interviewed. While non-response may have led to a biased estimate of the prevalence of the common mental disorders, it is unlikely to have affected estimates of associations with the exposures of interest. For this to have occurred, non-response would have to have been associated with both the likelihood of being a case of the common mental disorder and material standard of living (or social class). While it is possible that, for example, cases of the common mental disorders with the poorest material standard of living were less likely to participate than other cases, any such effect was unlikely to have been of sufficient magnitude to significantly change our main findings.

Like mortality and physical morbidity, common mental disorders are closely associated with poor material standard of living, independent of occupational social class. Although it is not yet known whether the adverse psychological effects of poor material standard of living are mediated by physical hardship, financial insecurity, impaired social relationships, or the perception of deprivation relative to the lifestyles of others, ${ }^{27}{ }^{50-53}$ risk factors such as low income and poor housing are probably more amenable to social and economic intervention than differences in occupational social class. Our findings support the view that changes in social and economic policy that reverse or reduce widening socioeconomic inequalities in Britain $^{54}$ will probably reduce the prevalence of common mental disorders. ${ }^{55} 56$

This study was started while SW was studying for the MSc in Epidemiology at the London School of Hygiene and Tropical Medicine. The data used in this manuscript were made available through the ESRC Data Archive. The data were originally colthrough the ESRC Data Archive. The data were originally collected by the ESRC Research Centre on Micro-social change at
the University of Essex. Neither the original collectors of the the University of Essex. Neither the original collectors of the
data nor the Archive bear any responsibility for the analyses or data nor the Archive bear any responsibility for the analyses or
interpretations presented here. I am grateful to Nick Buck of the interpretations presented here. I am grateful to Nick Buck of the
University of Essex for his description of the methods used to impute missing income data.

Funding: none.

Conflicts of interest: none.

1 Goldberg DP, Bridges K, Duncan-Jones P, Grayson D. Dimensions of neurosis seen in primary care settings. Psy-
chol Med 1987;17:461-70.

2 Eaton WW, Ritter C. Distinguishing anxiety and depression Eaton WW, Ritter C. Distinguishing anxiety and depress
with field survey data. Psychol Med 1988;18:155-66.

3 Goldberg D, Huxley P. Common mental disorders: a biopsychosocial approach. Routledge: London, 1992.
4 Lewis G. Dimensions of neurosis. Psychol Med 1992;22: 1011-18.

5 Kessler RC, McGonagle KA, Zhao S, et al. Lifetime and 12-month prevalence of DSM-III-R psychiatric disorders in the United States. Arch Gen Psychiatry 1994;51:8-19.

6 Meltzer H, Gill B, Petticrew M. OPCS Surveys of Psychiatric Morbidity in Great Britain. Report No 1. The prevalence of psychiatric morbidity among adults aged 16-64 living in private households in Great Britain. London: HMSO, 1995.

7 Williams P, Tarnopolsky A, Hand D, Shepherd M. Minor psychiatric morbidity and general practice consultations: the West London Survey. Psychol Med 1986; (monograph suppl 9): 1-37.

8 Cox BD, Blaxter M, Buckle ALJ, et al. The health and lifestyle survey. Cambridge: Health Promotion Research Trust, 1987.

9 Wells KB, Golding JM, Burnam MA. Psychiatric disorder and limitations in physical functioning in a sample of the Los Angeles general population. Am $\mathcal{F}$ Psychiatry 1988;145: 712-17.

10 Klerman GL. Depressive disorders. Further evidence for increased medical morbidity and impairment of social functioning. Arch Gen Psychiatry 1989;46:856-8.

11 Wohlfarth TD, van den Brink W, Ormel J, Koeter MWJ, Oldehinkel AJ. The relationship between social dysfunctioning and psychopathology among primary care attenders. Br F Psychiatry 1993;163:37-44.

12 Spitzer RL, Kroenke K, Linzer M, et al. Health-related quality of life in primary care patients with mental disorders. FAMA 1995;274:1511-17.

13 Murphy JM, Monson RR, Olivier DC, Sobol AM, Leighton AH. Affective disorders and mortality. A general population study. Arch Gen Psychiatry 1987;44:473-80.

14 Lloyd KR, Jenkins R, Mann A. Long term outcome of patients with neurotic illness in general practice. BMF 1996;313:26-8.

15 Jenkins R. Minor psychiatric disorder in employed young men and women and its contribution to sickness absence. Brf Industrial Med 1985;42:147-54

16 Croft-Jefferys C, Wilkinson G. Estimated costs of neurotic disorder in UK general practice. Psychol Med 1989;19:54958.

17 Lewis G, Wilkinson G. Another British disease? A recent increase in the prevalence of psychiatric morbidity in Britain. $\mathcal{F}$ Epidemiol Community Health 1993;47:358-61.

18 Blaxter M. Health and lifestyles. London: Routledge, 1990.

19 Dohrenwend BP. Socioeconomic status (SES) and psychiatric disorders: are the issues still compelling? Soc Psychiatry Psychiatr Epidemiol 1990;25:41-7.

20 Bruce ML, Takeuchi DT, Leaf PJ. Poverty and psychiatric status. Arch Gen Psychiatry 1991;48:470-4.

21 Rodgers B. Socio-economic status, employment and neurosis. Soc Psychiatry Psychiatr Epidemiol 1991;26:104-14.

22 Blazer DG, Kessler RC, McGonagle KA, Swartz MS. The prevalence and distribution of major depression in a national community sample: the National Comorbidity Survey. Am F Psychiatry 1994;151:979-86.

23 Brown GW, Harris T. Social origins of depression. London: Tavistock, 1978.

24 Bebbington P, Hurry J, Tennant C, Sturt E, Wing JK. Epidemiology of mental disorders in Camberwell. Psychol Med 1981;11:561-79.

25 Power C, Manor O. Explaining social class differences in psychological health among young adults: a longitudinal perspective. Soc Psychiatry Psychiatr Epidemiol 1992;27: 284-91.

26 Stansfeld SA, Marmot MG. Social class and minor psychiatric disorder in civil servants: a validated screening survey atric disorder in civil servants: a validated screening survey 1992;22:739-49.

27 Davey Smith G, Bartley M, Blane D. The Black Report on socioeconomic inequalities in health 10 years on. BMF 1990;301:373-7.

28 Whitehead M. Inequalities in health: the health divide. London: Penguin, 1992

29 Eames M, Ben-Shlomo Y, Marmot MG. Social deprivation and premature mortality: regional comparison across England. $B M F$ 1993;307:1097-102.

30 Sloggett A, Joshi H. Higher mortality in deprived areas: community or personal disadvantage? BMF 1994;309: 1470-4.

31 Buck N, Gershuny J, Rose D, Scott J, ed. Changing households: The British Household Panel Survey 1990-1992. Colchester: ESRC Research Centre on Micro-Social Change, 1994 .

32 Taylor MF, Brice J, Buck N, Prentice E, eds. British Household Panel Survey User Manual Volume A: Introduction, Technical Report and Appendices. Colchester: University of Essex, 1995

33 Goldberg DP, Williams P. The User's Guide to the General Health Questionnaire. Windsor: NFER-NELSON, 1988

34 Kendler KS, Heath AC, Martin NG, Eaves LJ. Symptoms of anxiety and symptoms of depression: same genes, different environments? Arch Gen Psychiatry 1987;44:451-7.

35 Mendels J, Weinstein N, Cochrane C. The relationship between depression and anxiety. Arch Gen Psychiatry 1972; 27:649-53.

36 Lewis G. Observer bias and the assessment of anxiety and depression. Soc Psychiatry Psychiatr Epidemiol 1991;26: $265-72$.

37 Marmot MG, Davey Smith G, Stansfeld S, et al. Health inequalities among British civil servants: the Whitehall II study. Lancet 1991;337:1387-93. 
38 Lewis $\mathrm{G}$, Booth $\mathrm{M}$. Regional differences in mental health in Great Britain. F Epidemiol Community Health 1992;46:608Great

39 Banks MH. Validation of the General Health Questionnaire in a young community sample. Psychol Med 1983;13:34953.

40 Anderson J, Huppert F, Rose G. Normality, deviance and minor psychiatric morbidity in the community. A population-based approach to General Health Questionnaire data in the Health and Lifestyle Survey. Psychol Med 1993;23:475-85.

41 Central Statistical Office. Social trends. London: HMSO, 1994.

42 Stata Corporation. Stata statistical software: release 4.0 College Station, Texas: Stata Corporation, 1995.

43 Huber PJ. Robust statistics. New York: John Wiley, 1981.

44 Armitage P, Berry G. Statistical methods in medical research. London: Blackwell, 1994.

45 Taylor A. Appendix: Sample characteristics, attrition and weighting. In: Buck N, Gershuny J, Rose D, Scott J, eds. Whanging households: The British Household Panel Survey 1990-1992. Colchester: ESRC Centre on Micro-Social 1990-1992. Colchester:

46 Dohrenwend BP, Levav I, Shrout PE, et al. Socioeconomic status and psychiatric disorders: the causation-selection issue. Science 1992;255:946-52.
47 Romans-Clarkson SE, Walton VA, Herbison GP, Mullen PE. Psychiatric morbidity among women in urban and rural New Zealand: psycho-social correlates. Br f Psychiatry 1990;156:84-91.

48 Regier DA, Farmer ME, Rae DS, et al. One-month prevalence of mental disorders in the United States and ociodemographic characteristics: the Epidemiologic Catchment Area study. Acta Psychiatr Scand 1993;88:35-47.

49 Jenkins R. Sex differences in minor psychiatric disorder. Psychol Med 1985; (monograph suppl 7):1-53.

50 Wilkinson R. Income distribution and life expectancy. BMF 1992;304:165-8.

51 Judge K. Income distribution and life expectancy: a critical appraisal. BMF 1995;311:1282-5.

52 Wilkinson RG. Commentary: A reply to Ken Judge: mistaken criticisms ignore overwhelming evidence. BMF 1995;311:1285-7.

53 Mackenbach JP, Looman CWN. Living standards and mortality in the European Community. F Epidemiol Community tality in the European
Health $1994 ; 48: 140-5$.

54 Hills J. Inquiry into income and wealth. York: Joseph Rowntree Foundation, 1995

55 Benzeval M, Judge K, Whitehead M, eds. Tackling inequalities in health. London: King's Fund, 1995.

56 BMA Board of Science and Education. Inequalities in health. London: BMA, 1995. 